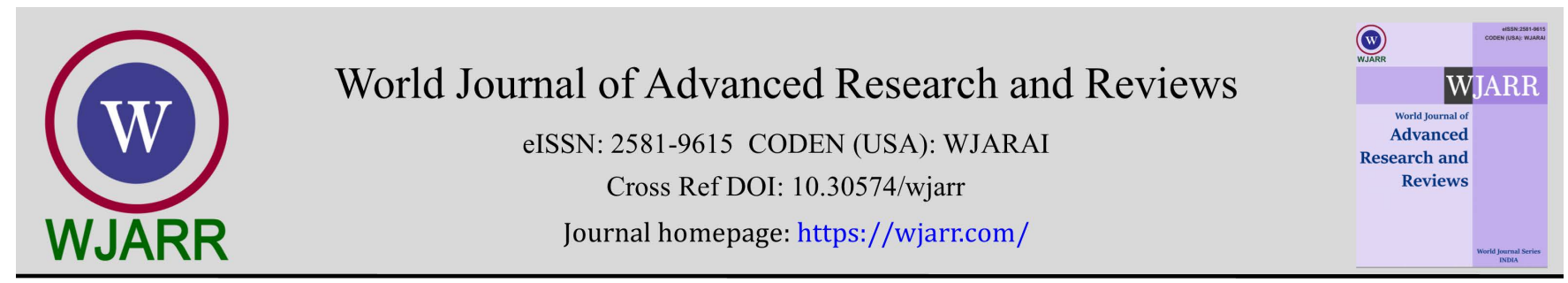

(REVIEW ARTICLE)

Check for updates

\title{
Cancer attrition immunotherapy
}

\author{
Michael John Dochniak*
}

Alleam, LLC, Minnesota, United States of America.

World Journal of Advanced Research and Reviews, 2021, 12(02), 626-631

Publication history: Received on 22 October 2021; revised on 28 November 2021; accepted on 30 November 2021

Article DOI: https://doi.org/10.30574/wjarr.2021.12.2.0649

\begin{abstract}
Cancer is a deadly disease wherein the immune system is inefficient, resulting in malignant tumors that metastasize. An active and robust immune system is the body's natural defense. Research efforts continue exploring alternative immunotherapies to fight cancer. This communication proposes non-infectious vaccines and hyper-allergenic skin creams to starve malignant tumors through immune metabolic interference.
\end{abstract}

Keywords: Cancer attrition; Immunotherapy; Immune metabolic interference; Inactivated vaccine; Hyper-allergenic skin cream

\section{Introduction}

Is a malignant tumor evading your immune system? Cancer is a leading cause of death worldwide, accounting for nearly 10 million deaths in 2020 [1]. In the United States, cancer represents a significant portion of total U.S. health care spending. Approximately 183 billion dollars in 2015 and a projected increase to 246 billion dollars by 2030 . For the millions of Americans diagnosed with cancer each year, the cost of treating the disease can be staggering [2].

Malignant tumors have atypical metabolism to satisfy an increased demand for energy and nutrients [3]. Cancer attrition immunotherapy proposes an "immune metabolic interference" mechanism to direct energy and nutrients away from malignant tumors. The major branches of adaptive immunity, cell-mediated and humoral, affect cytokine-mediated "reprogramming" of nutrient uptake and utilization to support the increased demands of adaptive immunity [4].

Cancer attrition immunotherapy is immunologically robust, metabolically expensive, innocuous, and financially inexpensive. A combination of FDA-approved vaccines and hyper-allergenic skin creams [5] stimulates adaptive immunity to promote cancer regression.

\section{Discussion}

Cancer attrition immunotherapy may be an effective and inexpensive treatment for malignant tumors and metastasis. A rate-limiting step in malignancy and metastasis is energy and nutrient consumption (i.e., cancer metabolism). Research indicates that immune hypometabolic states promote disease tolerance [6]. Cancer attrition immunotherapy (CAI) uses the adaptive immune system to starve malignant tumors through immune metabolic interference. Increased metabolic demands of forced adaptive immunity direct energy and nutrients away from malignant tumors. In continuation, CAI is robust and metabolically expensive based on the increased expression and variability of in vivo antibody formation.

\footnotetext{
${ }^{*}$ Corresponding author: Michael John Dochniak

Alleam, LLC, Minnesota, United States of America.

Copyright (C) 2021 Author(s) retain the copyright of this article. This article is published under the terms of the Creative Commons Attribution Liscense 4.0.
} 
The Centers for Disease Control and Prevention recommends influenza vaccines for routine use in adults with cancer [7]. Types of vaccines that may be useful in cancer attrition immunotherapy include killed/inactivated vaccines; liveattenuated vaccines; subunit, recombinant, polysaccharide, conjugate vaccines; and toxoid vaccines.

\section{Killed/inactivated vaccines}

The American Cancer Society communicates that patients are more likely to get infections in that the immune system is often less effective when cancerous tumors or treatments like radiation/chemotherapy insult the body [8].

Killed/inactivated vaccines do not cause infection and weaken the immune system because they are non-infectious particles from bacteria, viruses, and pathogens. Examples of FDA-approved vaccines include: Anthrax; Cholera; COVID19; Hepatitis A; Influenzas; Pertussis; Plague; Polio; Rabies; Tick-borne encephalitis; Typhoid; and Varicella-zoster virus.

The administration of the cholera vaccine may decrease colorectal cancer mortality. In a study published in Gastroenterology (2018) titled, "Cholera Vaccine Use Is Associated with a Reduced Risk of Death in Patients with Colorectal Cancer: A Population-Based Study." the researchers write, "The decrease in mortality with cholera vaccination was largely observed, irrespective of patient age or tumor stage at diagnosis or sex" [9].

COVID-19 vaccines are safe and effective for cancer patients struggling with their malignancy and therapies. In a review published in the Journal of Hematology and Oncology (2021) titled, "COVID-19 vaccines for patients with cancer: benefits likely outweigh risks." the researchers write, "Most current cancer therapeutics should not prevent the generation of protective immunity. We call for more research in this area and recommend that the majority of patients with cancer receive COVID vaccinations when possible" [10].

The Hepatitis-A vaccine administered to children with cancer is safe. In a study published in Pediatric hematology and oncology titled "Immunogenicity of hepatitis a vaccine in children with cancer." the authors write, "The hepatitis A vaccine was found to be effective and safe in children with cancer" [11].

The influenza vaccine does not affect "new-onset" immune-related adverse events in patients going through cancer immunotherapy. In an article published in Clinical Infectious Diseases (2020) titled, "Safety of Inactivated Influenza Vaccine in Cancer Patients Receiving Immune Checkpoint Inhibitors." the researchers concluded, "No increase in incidence or severity of immune-related adverse events was detected in patients on immune checkpoint inhibitors who received the inactivated influenza vaccine within approximately 2 months of immune checkpoint inhibitors. Routine seasonal flu vaccination is encouraged in patients on immune checkpoint inhibitors" [12].

The Pertussis vaccine can improve an immunity-based anti-tumor response. In an article published in Frontiers in Oncology (2021), titled "Repurposing Infectious Diseases Vaccines Against Cancer." the researchers write, "The recent approval of immunotherapies has rejuvenated this research area with reports of anti-tumor responses with existing infectious diseases vaccines used as such, either alone or in combination with immune checkpoint inhibitors" [13].

The varicella-zoster virus (VZV) vaccine is well-tolerated and efficacious in patients with solid tumors. In a clinical trial published in The Lancet. Infectious diseases (2019) titled, "Safety and efficacy of inactivated varicella-zoster virus vaccine in immunocompromised patients with malignancies: a two-arm, randomized, double-blind, phase 3 trial." the researchers concluded, "The inactivated VZV vaccine was well tolerated and efficacious for herpes zoster prevention in patients with solid tumor malignancies receiving chemotherapy" [14].

\section{Live-attenuated vaccines}

Live-attenuated vaccines contain a small amount of the weakened live virus, some patients should talk to their health care provider before receiving them, such as cancer patients with weakened immune systems [15].

The Centers for Disease Control and Prevention (CDC) communicates that the live-attenuated viral vaccines currently available and routinely recommended in the United States are measles, mumps, rubella (MMR combined vaccine), rotavirus, smallpox, chickenpox, yellow fever, and influenza (intranasal) [16].

Live-attenuated influenza vaccines are safe and effective for children with cancer. In an article published in the Journal of Infectious Diseases (2011) titled, "Safety and immunogenicity of live-attenuated and inactivated influenza vaccines 
in children with cancer." the researchers concluded, "As expected, serum antibody response against influenza A strains were greater with trivalent inactivated vaccine than with live-attenuated influenza vaccines in children with cancer. Both vaccines were well tolerated, and prolonged viral shedding after live-attenuated influenza vaccines was not detected" [17].

The smallpox vaccine is safe to use during cancer attrition immunotherapy. In a review published in the Clinical journal of oncology nursing (2004) titled, "Oncology nursing implications related to smallpox bioterrorism preparations." author Kelly Mack writes, "Patients with cancer are at particular risk for complications from the smallpox vaccine because of potential immunosuppression. Vaccinated nurses caring for these patients also need to take special precautions because of the possibility of secondary transmission of this live vaccine to patients" [18].

Early childhood vaccinations are protective of cancer. In a meta-analysis published in Scientific Reports (2017) titled, "Early vaccination protects against childhood leukemia: A systematic review and meta-analysis." the researchers concluded, "Early vaccination appears to be associated with a reduced risk of childhood leukemia" [19].

The varicella vaccine may not be safe in immunosuppressed children with cancer. In a study published in the European journal of haematology (2004) titled, "Immunogenicity of a two-dose regime of varicella vaccine in children with cancers." the researchers concluded, "The safety of chickenpox vaccine in these immunosuppressed children needs to be further studied" [20].

The yellow fever vaccine may be a new cancer treatment. In an observational study published in the European Journal of Cancer Prevention (2018) titled, "Yellow fever vaccine 17D administered to healthy women aged between 40- and 54-years halves breast cancer risk: an observational study." the researchers write, "Yellow fever vaccine 17D expresses a protein with a closely homologous epitope. Cross-reactive immunity could hypothetically inhibit breast cancer growth at least in women aged around 50 years at diagnosis, in whom the prognosis of breast cancer was found to be better than that in women younger or older" [21].

\section{Messenger RNA vaccines}

Messenger RNA (mRNA) vaccines make proteins to trigger an immune response. MRNA vaccines have several benefits compared to other types of vaccines, including shorter manufacturing times and, because they do not contain a live virus, no risk of causing disease in the cancer patient getting vaccinated. COVID-19 is an example of an mRNA vaccine [22].

The Covid-19 vaccine is safe and effective in adolescents and young adults with tumors. In a comparative study published in the European Journal of Cancer (2021) titled, "The BNT162b2 mRNA COVID-19 vaccine in adolescents and young adults with cancer: A monocentric experience." the researchers concluded, "We report the good safety profile and good efficacy of the BNT162B2 vaccine in adolescents and young adults with solid tumors" [23].

Most cancer patients going through immunotherapy can safely receive a COVID-19 vaccine. In an article published in the Journal of hematology \& Oncology (2021) titled, "COVID-19 vaccines for patients with cancer: benefits likely outweigh risks." the researchers write, "We summarize the current data on leading COVID-19 vaccine candidates and vaccination of patients undergoing immunomodulatory cancer treatments. Most current cancer therapeutics should not prevent the generation of protective immunity. We call for more research in this area and recommend that the majority of patients with cancer receive COVID vaccinations when possible" [24].

\section{Toxoid vaccines}

These vaccines use a toxin (harmful product) made by the germ that causes a disease. They create immunity to germ parts (i.e., toxins) that cause disease. Toxoid vaccines protect against diphtheria and tetanus [25].

Toxoid vaccines may strengthen the anti-tumor immune response. In an article published in Cancer Research (2020) titled, "Exploiting Preexisting Immunity to Enhance Oncolytic Cancer Immunotherapy." the researchers write, "These findings establish a novel technology that enhances oncolytic cancer immunotherapy by capitalizing on pre-acquired immunity to pathogens to convert a weak anti-tumor immune response into a much stronger one" [26]. 


\section{Subunit, recombinant, polysaccharide, and conjugate vaccines}

These vaccines use specific pieces of a germ-like its protein, sugar, or capsid (a casing around the germ). These noninfectious vaccines give a very strong immune response that targets key parts of the germ. They can also be used on almost everyone who needs them, including cancer patients with a weakened immune system [27].

\section{Hyper-allergenic skin creams}

Hyper-allergenic skin creams activate the humoral arm of adaptive immunity and may be useful in cancer attrition immunotherapy. An allergen is a harmless substance that can cause the immune system to make IgE antibodies. It has been proposed that forced atopy may shift the body's resource allocation away from metastasizing cells to IgE-primed effector-cell proliferation [28].

In United States Patent application number 20210015912 A1 (2019) titled, "Topical hyper-allergenic composition and method of treating using the same" the applicant states, "There is a need for a composition that induces a hyperallergenic response in an individual and induces the individual to produce IgE-primed effector cells that bind endogenous-proteins associated with metastatic cancer" [29].

Atopic dermatitis does not increase the risk of most cancers. In an original investigation published by JAMA Dermatology (2020) titled, "Association Between Atopic Eczema and Cancer in England and Denmark." the researchers concluded, "In this study, no evidence was found that people with atopic eczema are at increased risk of most cancers" [30].

Immunotherapy using a combination of non-infectious vaccines [31] and hyper-allergenic skin creams [32] may be an effective and inexpensive approach to fighting cancer. Proinflammatory cytokines secreted by cells involved in the inflammatory process play a role in cellular and humoral immune response [33].

A limitation of cancer attrition immunotherapy may be an increased incidence of cytokine storms or cytokine release syndrome during forced adaptive immunity [34, 35].

\section{Conclusion}

Research efforts continue to explore effective and inexpensive immunotherapies to improve outcomes for patients with malignant tumors. Cancer attrition immunotherapy proposes non-infectious vaccines and hyper-allergenic skin creams to starve malignant tumors through immune metabolic interference.

\section{Compliance with ethical standards}

\section{Acknowledgments}

The author would like to thank Denise Harmony Dunn for partial editing.

\section{Author disclosure}

Michael J. Dochniak is cofounder of Alleam, LLC, Minnesota, and United Sates of America. This commentary contains a discussion of an unapproved/ investigative hyper-allergenic skin cream to promote cancer regression.

The author is co-founder of Alleam, LLC. Minnesota, United States of America.

\section{References}

[1] Cancer. World Health Organization. 21 September 2021. Available from: https://www.who.int/news-room/factsheets/detail/cancer

[2] The Cost of Cancer. American Cancer Society. 2020. Available from: https://www.cancer.org/research/cancerfacts-statistics/all-cancer-facts-figures/cancer-facts-figures-2020.html

[3] Zhang Y, Jin-Ming Y. Altered energy metabolism in cancer: a unique opportunity for therapeutic intervention. Cancer biology \& therapy. 2013; 14(2): 81-9. Available from: https://pubmed.ncbi.nlm.nih.gov/23192270/ doi: 10.4161/cbt.22958. 
[4] Spurlock M. Regulation of metabolism and growth during immune challenge: an overview of cytokine function. J. Anim. Sci. 75: 1773-1783. Available from: https://pubmed.ncbi.nlm.nih.gov/9222833/ doi: 10.2527/1997.7571773x.

[5] Dochniak M. Metastasis and immune-metabolic interference, Journal of Medical and Biological Science. May 2020; 6(2): 11-13. Available from: https://www.pearlresearchjournals.org/journals/jmbsr/archive/2020/May/PDF/Dochniak\%20.pdf

[6] Ganeshan K, Nikkanen J, Man K, Leong YA, Sogawa Y, Maschek JA, Van Ry T, Chagwedera DN, Cox JE, Chawla A. Energetic Trade-Offs and Hypometabolic States Promote Disease Tolerance. Cell. 4 Apr 2019; 177(2): $399-413$. Available from: https://www.ncbi.nlm.nih.gov/pmc/articles/PMC6456449/ doi: 10.1016/j.cell.2019.01.050

[7] Cancer and Flu. CDC. August 2021. Available from: https://www.cdc.gov/cancer/flu/index.htm

[8] Why People with Cancer Are More Likely to Get Infections. American Cancer Society. (C) 2021. Available from: https://www.cancer.org/treatment/treatments-and-side-effects/physical-side-effects/low-bloodcounts/infections/why-people-with-cancer-are-atrisk.html\#: :text=People\%20with\%20cancer\%20may\%20have,body\%20systems\%20in\%20different\%20way S.

[9] Ji J, Sundquist J, Sundquist K. Cholera Vaccine Use Is Associated with a Reduced Risk of Death in Patients with Colorectal Cancer: A Population-Based Study. Gastroenterology. Jan 2018; 154(1): 86-92. Available from: https://pubmed.ncbi.nlm.nih.gov/28923497/ doi: 10.1053/j.gastro.2017.09.009.

[10] Hwang JK, Zhang T, Wang AZ, Li Z. COVID-19 vaccines for patients with cancer: benefits likely outweigh risks. J Hematol Oncol. 27 Feb 2021; 14(1): 38. Available from: https://pubmed.ncbi.nlm.nih.gov/33640005/ doi: 10.1186/s13045-021-01046-w.

[11] Köksal Y, Yalçin B, Aydin GB, Sari N, Yazici N, Varan A, Kutluk T, Akyüz C, Büyükpamukçu M. Immunogenicity of hepatitis a vaccine in children with cancer. Pediatr Hematol Oncol. Dec 2006; 23(8): 619-24. Available from: https://pubmed.ncbi.nlm.nih.gov/17065137/ doi: 10.1080/08880010600907239.

[12] Chong CR, Park VJ, Cohen B, Postow MA, Wolchok JD, Kamboj M. Safety of Inactivated Influenza Vaccine in Cancer Patients Receiving Immune Checkpoint Inhibitors. Clin Infect Dis. 2 Jan 2020; 70(2): 193-199. Available from: https://pubmed.ncbi.nlm.nih.gov/30874791/ doi: 10.1093/cid/ciz202.

[13] Vandeborne L, Pantziarka P, Van Nuffel AMT, Bouche G. Repurposing Infectious Diseases Vaccines Against Cancer. Front Oncol. 13 May 2021; 11: 688755. Available from: https://pubmed.ncbi.nlm.nih.gov/34055652/ doi: $10.3389 /$ fonc.2021.688755.

[14] Mullane KM, Morrison VA, Camacho LH, Arvin A, McNeil SA, Durrand J, Campbell B, Su SC, Chan ISF, Parrino J, Kaplan SS, Popmihajlov Z, Annunziato PW; V212 Protocol 011 Trial Team. Safety and efficacy of inactivated varicella zoster virus vaccine in immunocompromised patients with malignancies: a two-arm, randomised, double-blind, and phase 3 trial. Lancet Infect Dis. Sep 2019; 19(9): 1001-1012. Available from: https://pubmed.ncbi.nlm.nih.gov/31399378/doi: 10.1016/S1473-3099(19)30310-X.

[15] Live-attenuated vaccines. HHS.gov. 29 April $2021 . \quad$ Available from: https://www.hhs.gov/immunization/basics/types/index.html

[16] Wodi P. Morelli BA. Principles of Vaccination. CDC.gov. 2021 August 18. Available from: https://www.cdc.gov/vaccines/pubs/pinkbook/prinvac.html

[17] Carr S, Allison KJ, Van De Velde LA, Zhang K, English EY, Iverson A, Daw NC, Howard SC, Navid F, RodriguezGalindo C, Yang J, Adderson EE, McCullers JA, Flynn PM. Safety and immunogenicity of live attenuated and inactivated influenza vaccines in children with cancer. J Infect Dis. 2011; 204(10): 1475-82. Available from: https://pubmed.ncbi.nlm.nih.gov/21949042/ doi: 10.1093/infdis/jir561.

[18] Mack K. Oncology nursing implications related to smallpox bioterrorism preparations. Clinical journal of oncology nursing. 2004; 8(1): 51-5. Available from: https://pubmed.ncbi.nlm.nih.gov/14983764/ doi: 10.1188/04.CJON.51-55.

[19] Morra ME, Kien ND, Elmaraezy A, Abdelaziz OAM, Elsayed AL, Halhouli O, Montasr AM, Vu TL, Ho C, Foly AS, Phi AP, Abdullah WM, Mikhail M, Milne E, Hirayama K, Huy NT. Early vaccination protects against childhood leukemia: A systematic review and meta-analysis. Sci Rep. 22 Nov 2017; 7(1): 15986. Available from: https://pubmed.ncbi.nlm.nih.gov/29167460/ doi: 10.1038/s41598-017-16067-0. 
[20] Leung TF, Li CK, Hung EC, Chan PK, Mo CW, Wong RP, Chik KW. Immunogenicity of a two-dose regime of varicella vaccine in children with cancers. Eur J Haematol. May 2004; 72(5): 353-7. Available from: https://pubmed.ncbi.nlm.nih.gov/15059071/ doi: 10.1111/j.1600-0609.2004.00216.x

[21] Mastrangelo G, Pavanello S, Fadda E, Buja A, Fedeli U. Yellow fever vaccine 17D administered to healthy women aged between 40 and 54 years halves breast cancer risk: an observational study. Eur J Cancer Prev. Jul 2018; 27(4): 303-309. Available from: https://pubmed.ncbi.nlm.nih.gov/27870643/ doi: 10.1097/CEJ.0000000000000333.

[22] mRNA Vaccines. HHS.gov. 29 April $2021 . \quad$ Available from: https://www.hhs.gov/immunization/basics/types/index.html

[23] Revon-Riviere G, Ninove L, Min V, Rome A, Coze C, Verschuur A, de Lamballerie X, André N. The BNT162b2 mRNA COVID-19 vaccine in adolescents and young adults with cancer: A monocentric experience. Eur J Cancer. Sep 2021; 154: 30-34. Available from: https://pubmed.ncbi.nlm.nih.gov/34233234/ doi: 10.1016/j.ejca.2021.06.002.

[24] Hwang JK, Zhang T, Wang AZ, Li Z. COVID-19 vaccines for patients with cancer: benefits likely outweigh risks. J Hematol Oncol. 27 Feb 2021; 14(1): 38. Available from: https://pubmed.ncbi.nlm.nih.gov/33640005/ doi: 10.1186/s13045-021-01046-w.

[25] Toxoid Haccine. HHS.gov. April $2021 . \quad$ Available from: https://www.hhs.gov/immunization/basics/types/index.html

[26] Tähtinen S, Feola S, Capasso C, Laustio N, Groeneveldt C, Ylösmäki EO, Ylösmäki L, Martins B, Fusciello M, Medeot M, Tagliamonte M, Chiaro J, Hamdan F, Peltonen K, Ranki T, Buonaguro L, Cerullo V. Exploiting Preexisting Immunity to Enhance Oncolytic Cancer Immunotherapy. Cancer Res. 15 Jun 2020; 80(12): 2575-2585. Available from: https://pubmed.ncbi.nlm.nih.gov/32107211/doi: 10.1158/0008-5472.CAN-19-2062.

[27] Subunit, recombinant, polysaccharide, and conjugate vaccines. HHS.gov. 21 April 2021. Available from: https://www.hhs.gov/immunization/basics/types/index.html

[28] Dochniak MJ. Maladaptive immunity and metastasizing cancer. Cancer Med J. 2020; 3: 31-34. Available from: https://www.tridhascholars.org/pdfs/maladaptive-immunity-and-metastasizing-cancer-CMJ-03-1017.pdf

[29] Dochniak MJ, Alleam LLC, assignee. Topical hyper-allergenic composition and method of treating using the same. United States Patent application number 20210015912 A1. 16 July 2019.

[30] Mansfield KE, Schmidt SAJ, Darvalics B, Mulick A, Abuabara K, Wong AYS, Sørensen HT, Smeeth L, Bhaskaran K, Dos Santos Silva I, Silverwood RJ, Langan SM. Association Between Atopic Eczema and Cancer in England and Denmark. JAMA Dermatol. 1 Oct 2020; 156(10): 1086-1097. Available from: https://pubmed.ncbi.nlm.nih.gov/32579178/ doi: 10.1001/jamadermatol.2020.1948.

[31] How to Pay. HHS.gov. 29 April 2021. Available from: https://www.hhs.gov/immunization/getvaccinated/pay/index.html

[32] Confronting Metastatic Cancer through Forced Atopy (many allergies), Alleam, LLC. Available from http://alleamit.com/

[33] Pietruczuk A, Zajkowska JM, Hermanowska-Szpakowicz T. Cytokiny prozapalne w odpowiedzi humoralnej [Proinflammatory cytokines in humoral immune response]. Pol Merkur Lekarski. Nov 2001; 11(65): $434-7$. Available from: https://pubmed.ncbi.nlm.nih.gov/11852818/

[34] Tisoncik JR, Korth MJ, Simmons CP, Farrar J, Martin TR, Katze MG. Into the eye of the cytokine storm. Microbiol Mol Biol Rev. Mar 2012; 76(1): 16-32. Available from: https://pubmed.ncbi.nlm.nih.gov/22390970/ doi: 10.1128/MMBR.05015-11.

[35] Shimabukuro-Vornhagen A, Gödel P, Subklewe M, Stemmler HJ, Schlößer HA, Schlaak M, Kochanek M, Böll B, von Bergwelt-Baildon MS. Cytokine release syndrome. J Immunother Cancer. 15 Jun 2018; 6(1): 56 Available from: https://www.ncbi.nlm.nih.gov/pmc/articles/PMC6 doi: 10.1186/s40425-018-0343-9 